\title{
Thermal stability of directly UV-written waveguides and devices
}

\author{
Kulstad, K.; Svalgaard, Mikael
}

Published in:

Proceedings of the 24th European Conference on Optical Communication

Link to article, DOI:

10.1109/ECOC.1998.732421

Publication date:

1998

Document Version

Publisher's PDF, also known as Version of record

Link back to DTU Orbit

Citation (APA):

Kulstad, K., \& Svalgaard, M. (1998). Thermal stability of directly UV-written waveguides and devices. In

Proceedings of the 24th European Conference on Optical Communication (Vol. Volume 1, pp. 33-34). IEEE. https://doi.org/10.1109/ECOC.1998.732421

\section{General rights}

Copyright and moral rights for the publications made accessible in the public portal are retained by the authors and/or other copyright owners and it is a condition of accessing publications that users recognise and abide by the legal requirements associated with these rights.

- Users may download and print one copy of any publication from the public portal for the purpose of private study or research.

- You may not further distribute the material or use it for any profit-making activity or commercial gain

- You may freely distribute the URL identifying the publication in the public portal

If you believe that this document breaches copyright please contact us providing details, and we will remove access to the work immediately and investigate your claim. 


\title{
THERMAL STABILITY OF DIRECTLY UV-WRITTEN WAVEGUIDES AND DEVICES
}

\section{Kaj Kulstad and Mikael Svalgaard}

\author{
Microelectronics Center, Bldg. 345 east, Technical University of Denmark \\ kaj@mic.dtu.dk \\ svlgrd@mic.dtu.dk
}

\begin{abstract}
Accelerated aging experiments of directly UV-written straight waveguides, $s$-bends and directional couplers have been made. The results show that these structures are nearly unaffected by thousands of thermal cycles between $+22{ }^{\circ} \mathrm{C}$ and $+80^{\circ} \mathrm{C}$.
\end{abstract}

\section{Introduction}

A number of processes have been explored for fabrication of silica-on-silicon based planar waveguide devices, most of them involving a fairly large number of process steps consisting of glass film deposition, photolithography and etching procedures [1]. We have recently shown that waveguides and devices may alternatively be directly written into a photosensitive glass sample that is scanned under a focussed ultraviolet (UV) laser beam $[2,3]$. This method yields high quality devices, has the advantage of involving very few process steps and has sufficient capacity for mass production [4]. It is well known from work involving fiber Bragg gratings that UV induced index changes generally are unstable over extended periods of time due to therma bleaching of optically induced defect centers [5]. Since directly written planar waveguide devices consist entirely of such defects the index-change stability requirements may be much more stringent than what is currently accepted for devices based on fiber Bragg gratings where the UV exposed region only constitutes a small fraction of the total device layout. It is therefore of great importance to investigate the long-term stability of directly UV written devices.

In this paper we present results from accelerated aging experiments of directly written straight waveguides, s-bends and directional couplers.

\section{Experimental (UV writing)}

Planar waveguides have been written into a photosensitive glass film using a focussed $244 \mathrm{~nm}$ continuous wave UV laser and high precision, three dimensional translation stages [2]. The sample used here is fabricated by plasma enhanced chemical vapour deposition and consists of a three layer silica film waveguide on a silicon wafer. The film waveguide core layer is $\sim 2.5 \mu \mathrm{m}$ thick and contains about 13 mole $\% \mathrm{GeO}_{2}\left[^{2}\right]$. The UV spot diameter on the sample was $5 \mu \mathrm{m}$ and the incident power was $17 \mathrm{~mW}$. The sample was prior to the UV exposure loaded with -2 mole $\% \mathrm{D}_{2}$ to increase the photosensitivity. After UV processing the sample is annealed at $80^{\circ} \mathrm{C}$ for several days to permit outdiffusion of residual $\mathrm{D}_{2}$.

\section{Experimental (accelerated aging)}

Insertion loss measurements were performed at room temperature by launching light from a $1.54 \mu \mathrm{m}$ diode laser through the waveguides using butt coupled standard telecom fibers. Prior to the accelerated aging experiments the sample was subjected to a four hour pre-annealing at $150{ }^{\circ} \mathrm{C}$, thereby removing the most unstable defect centers and increasing the stability of the remaining structure. The accel- erated aging experiments were carried out by placing the sample on a vacuum chuck, were the temperature could be varied from a room temperature of $22{ }^{\circ} \mathrm{C}$ and up to $80^{\circ} \mathrm{C}$. This temperature range was chosen to resemble that used for the testing described in the Bellcore specifications [6]. The upward cycling took 3 minutes while the downward cycling took 12 minutes, resuiting in a total cycling time of $15 \mathrm{~min}$ utes. The sample has been cycled in this way for over 700 hours $(2800+$ cycles $)$.

\section{Results (linear and curved waveguides)}

The linear waveguides each contain a Bragg grating that was photoinduced with an excimer laser and a phasemask. The Bragg wavelength is $\sim 1.56 \mu \mathrm{m}$ and could be determined to an accuracy of $\pm 0.05 \mathrm{~nm}$ using a broad band light source and an optical spectrum analyser. The effective index of the guided mode can be determined from $n_{\text {eff }}=\lambda_{\text {Bragg }}$ $12 \Lambda_{0}$, where $n_{\text {eff }}$ is the effective refractive index of the guided mode and $\Lambda_{0}$ is the period of the phase mask. Hence, these gratings serve as an accurate indicator of the effective index of the host waveguide. Part of the sample contains linear (reference) waveguides without Bragg grating and waveguides made up from multiple s-bends [3]. The s-bends consist of circular arcs with a radius of curvature of 10 , $13.5,20$ and $30 \mathrm{~mm}$ and a transverse displacement of 100 $\mu \mathrm{m}$. Each waveguide contains four s-bends in series to increase the measurement sensitivity towards changes in the sbend properties.

Bragg wavelength and insertion loss measurements were carried out at $0,300,800,1600$ and 2800 cycles. No change in the Bragg wavelength could be discerned throughout the cycling experiment; i.e. any changes in the effective index must be smaller than $\pm 5 \times 10^{-5}$. In addition, no change in the excess loss of the different $\mathrm{s}$-bends could be observed within the measurement accuracy of $\pm 0.15 \mathrm{~dB}$.

\section{Results (Directional couplers)}

The sample also contains several four port directional couplers, which should be much more sensitive towards small changes of the UV induced index change than isolated waveguides. The couplers were written with a $9 \mu \mathrm{m}$ waveguide center-to-center spacing in the central coupling region and the length of this region, $\mathrm{L}$, was varied from 500 $\mu \mathrm{m}$ to $2600 \mu \mathrm{m}$ [4]. The coupler excess loss compared to a linear reference waveguide is typically a few tenths of a dB and the coupling ratio is symmetrical with respect to which input arm is excited.

The normalised coupling ratio is defined by $\alpha=P_{1} /\left(P_{1}+P_{2}\right)$, where $P_{1}$ and $P_{2}$ is the power measured at output arm 1 and 
2 , respectively. From coupled mode theory, it follows $\left[{ }^{7}\right]$ that the normalised coupling ratio is given by:

$$
\alpha=1-F^{2} \sin ^{2}\left(0.5 \pi(L+\Delta L) / L_{c}\right)
$$

where $F^{2}$ is the maximum fraction of the total power that can be transferred from one waveguide to the other. $\mathrm{L}_{\mathrm{c}}$ is the coupling length and $\Delta \mathrm{L}$ is a change in the effective length of the linear coupling region due to coupling occurring in the bends. This form of the coupling ratio has been fitted to the measured values as a function of the coupling length, thereby yielding values for $\mathrm{F}^{2}, \mathrm{~L}_{\mathrm{c}}$ and $\Delta \mathrm{L}$. In figure $1 \Delta \mathrm{L}$ and $\mathrm{L}_{\mathrm{c}}$ are plotted versus the number of cycles, while $\mathrm{F}^{2}$ is plotted in figure 2. Both $\Delta \mathrm{L}$ and $\mathrm{L}_{\mathrm{c}}$ change only very slightly throughout the experiment; after 2800 cycles $\Delta \mathrm{L}$ appears to have decreased by $\sim 2 \%$ while $\mathrm{L}_{c}$ has decreased by $\sim 4 \%$. Decreasing coupling lengths are consistent with a slightly decreasing index change leading to slightly less confined mode profiles and thus also a greater mode overlap integral and hence a more rapid power transfer. The meas ured values for $\mathrm{F}^{2}$ shows a gradual decrease from about 0.984 to 0.968 . The measured excess loss of the couplers remained unaffected by the cycling. It should be possible to reduce the observed changes in the coupling parameters even further by increasing the pre-annealing temperature, as suggested in reference 5 .

Fig. 1: The coupler parameters $\Delta L$ and $L_{c}$ versus the number of thermal cycles

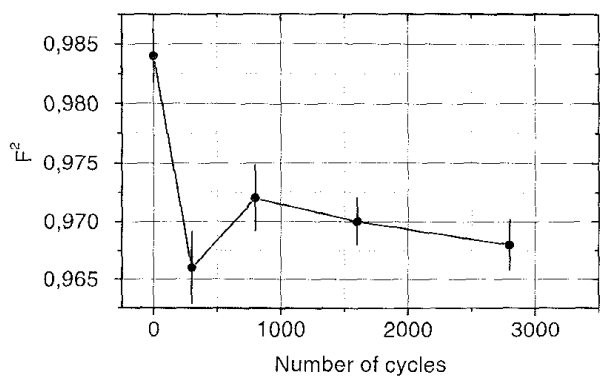

Fig. 2: The maximum fraction of power transferred between the waveguides versus the number of thermal cycles.

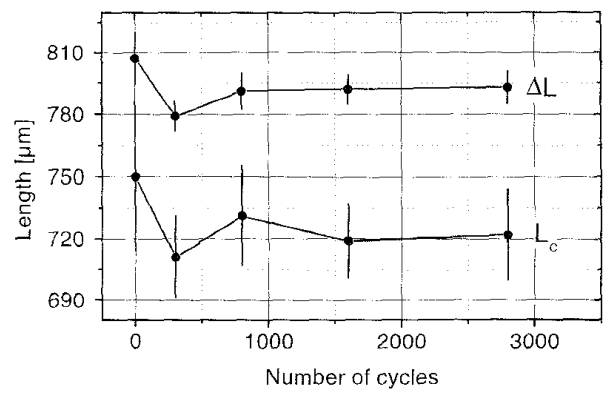

\section{Conclusion}

The performance of directly UV-written waveguides and devices is shown to be affected very little by thousands of thermal cycles between $+22{ }^{\circ} \mathrm{C}$ and $+80^{\circ} \mathrm{C}$. For linear waveguides and s-bends no effects could be seen. For directional couplers the coupling length varies by less than $2 \%$ while the excess loss remains unaffected.

\section{References}

/1 M. Kawachi: 'Silica waveguides on silicon and their application to integrated-optical components', Optical and Quantum Electronics, Vol. 22, (1990) 391-416

12) M. Svalgaard, C.V. Poulsen, A. Bjarklev and O. Poulsen: 'Direct UV-writing of buried single-mode channel waveguides in Ge-doped silica films', Electronic Letters, Vol. 30, No. 17 (1994) 1401-1402

13/ M. Svalgaard and M. Kristensen: 'Directly UV written silica-on-silicon planar waveguides with low loss', Electronic Letters, Vol. 33, No. 10, (1997) 861-862

14/ M. Svalgaard: 'Direct writing of planar waveguide power splitters and directional couplers using a focused ultraviolet laser beam', Electronic Letters, Vol. 33, No. 20 , (1997) 1694-1695

15/ T. Erdogan, V. Mizrahi, P. J. Lemaire and D. Monroe: 'Decay of ultraviolet-induced Bragg gratings', J. Appl. Phys., Vol. 76, No. 1, (1994) 73-80

16/ TR-NWT-001209, 'Generic Requirements for Passive Fibre Optic Component Reliability Assurance Practise' Bellcore, Issue 1, March 1992

17) A.W. Snyder and J.D. Love: 'Optical Waveguide The ory', Chapman \& Hall, 1993. 